\title{
CHAIRMEN JOINT CHIEFS OF STAFF'S LEADERSHIP USING THE JOINT STRATEGIC PLANNING SYSTEM IN THE 1990s: \\ RECOMMENDATIONS FOR STRATEGIC LEADERS
}

Colonel Richard M. Meinhart

June 2003 